\title{
ВЛИЯНИЕ КОНТРОЛИРУЕМОЙ ДЕЗАКТИВАЦИИ НА СВОЙСТВА НАНЕСЁННОГО НИКЕЛЕВОГО КАТАЛИЗАТОРА В РЕАКЦИЯХ ЖИДКОФАЗНОЙ ГИДРОГЕНИЗАЦИИ КРАТНЫХ УГЛЕРОДНЫХ СВЯЗЕЙ
}

\author{
А. В. Афинеевский, Д. А. Прозоров, А. В. Князев, К.А. Никитин \\ АНДРЕЙ ВЛАДИМИРОВИЧ АФИНЕЕВСКИЙ - кандидат химических наук, научныій сотрудник кафедры \\ физической и коллоидной химии, НИИ Термодинамики и кинетики химических проиессов (ФГБОУ ВО \\ «ИГХТУ»). Область научных интересов: катализ, адсорбиия в катализе, жидкофазное гидрирование. \\ E-mail: afineevskiy@mail.ru.
}

ДМИТРИЙ АЛЕКСЕЕВИЧ ПРОЗОРОВ - кандидат химических наук, научный сотрудник кафедры физической и коллоидной химии, НИИ Термодинамики и кинетики химических проиессов (ФГБОУ ВО «ИГХТУ»). Область научных интересов: катализ, адсорбция в катализе, жидкофазное гидрирование. E-mail:prozorovda@mail.ru.

АЛЕКСАНДР ВЛАДИМИРОВИЧ КНЯЗЕВ - доктор химических наук, профессор, декан химического факультета, Национального исследовательского Нижегородского государственного университета имени Н.И. Лобачевского (Университет Лобачевского, ННГУ). Область научных интересов: химическая термодинамика неорганических и органических соединений. E-mail: knyazevav@gmail.ru.

КИРИЛЛ АНДРЕЕВИЧ НИКИТИН - магистрант кафедры химии и технологии высокомолекулярных соединений ФГБОУ ВО «ИГХТУ»). Область научных интересов: катализ, механохимия, жидкофазное гидрирование.E-mail: kirillnikitin09@gmail.com.

153000, Россия, Иваново, Шереметевский пр., д. 7. НИИ Термодинамики и кинетики химических прочессов Ивановского государственного химико-технологического университета (ФГБОУ ВО «ИГХТУ»). Тел. (4932) 30-73-46.

603950, Россия, Нижний Новгород, пр. Гагарина, 23, корпус 5, ФГАОУ ВО «Национальный исследовательский Нижегородский государственный университет им. Н.И. Лобачевского» (ННГУ). Тел. (831) 462-30-85.

Исследовано влияние контролируемой дезактивации $\mathrm{Ni} / \mathrm{SiO}$ катализаторов в реакииях жидкофазного восстановления двойной связи молекуль диэтилового эфира малеиновой кислоты (ДЭМК). Изучено влияние общего количества нанесённого на силикагель металла и количества восстановленного металла на структурно-механические и каталитические свойства катализатора. Показано влияние сульфидирования поверхности на каталитические свойства активного металла в зависимости от прочента нанесения оксида никеля. Экспериментально доказано практическое отсутствие относительной структурной чувствительности нанесённых катализаторов. Относительная структурная чувствительность катализатора численно может быть выражена как фрактальная размерность поверхности исследуемых образиов $\mathrm{Ni} \% \mathrm{SiO}_{2}$ после протекания одного из технологических процессов, отнесённая к фрактальной размерности свежеприготовленного никелевого катализатора. Рассмотрена относительная структурная чувствительность поверхности катализатора под влиянием различного гидродинамического режима, повышенного давления, природы растворителя, адсорбиии реагирующих веществ, протекания реакиий гидрогенизачии, проиесса дезактивации. Установлено, что в ходе процесса синтеза, предварительного насыщения катализатора водородом в реакторе, протекании реакиии восстановления ДЭМК, проиесса дезактиваиии сульфид-ионом, поверхность катализатора претерпевает определённые изменения - увеличивается 
шероховатость поверхности, уменьшается размер агломератов и кристаллитов. Проведено исследование процесса частичной контролируемой дезактивации активных ичентров никеля сульфид-ионом на активность нанесённых катализаторов, рассчитаны соотношения поверхностных атомов никеля, водорода и серы в каталитических системах, обладающих различной активностью. Показано, что при дезактивации поверхности никелевого катализатора сульфид-ионами в пропорциях 1 атом серы на 2 поверхностных атома никеля активность катализатора снижается на $90 \%$ и впоследствии не восстанавливается.

Ключевые слова: жидкофазная гидрогенизация, диэтиловый эфир малеиновой кислоты, модифицирующие агенты, скелетный и нанесённый никелевый катализатор, активный металл, эффект структурной чувствительности катализатора.

\title{
THE CONTROLLED DEACTIVATION EFFECT ON THE PROPERTIES OF A SUPPORTED NICKEL CATALYST IN REACTIONS OF LIQUID PHASE HYDROGENIZATION OF MULTIPLE BONDS “CARBON-CARBON"
}

\author{
A.V. Afineevskii, D.A. Prozorov, A. V. Knyazev, K.A. Nikitin \\ 7, Sheremetievskiy Avenue, Ivanovo, 153000, Russia. Ivanovo state university of chemistry and technology. \\ 23, Prospekt Gagarina (Gagarin Avenue) BLDG 2, 2nd floor, Nizhnij Novgorod, 603950, Russia. Lobachevsky State \\ University of Nizhny Novgorod.
}

The effect of controlled deactivation of $\mathrm{Ni} / \mathrm{SiO}$, catalysts in the reactions of liquid-phase reduction of the double bond of maleic acid diethyl ether molecule (MADE) was studied. The influence of the quantity of supported metal and the quantity of reduced metal on the structural-mechanical and catalytic properties of nickel deposited on silica gel were studied. The influence of surface sulfidation on the catalytic properties of the active metal is shown as a function of the percentage deposition of nickel oxide. The practical absence of the relative structural sensitivity of the supported catalysts has been experimentally proved. The relative structural sensitivity of the catalyst can be calculated as the fractal dimension of the surface of the $\mathrm{Ni}^{\circ} / \mathrm{SiO}_{2}$ samples studied after one of the technological processes has passed, referred to the fractal dimension of the freshly prepared catalyst. The relative structural sensitivity of the catalyst surface under the influence of various hydrodynamic regimes, pressure increased and the nature of the solvent, the adsorption of reactants, the course of hydrogenation reactions and the deactivation process is considered. It has been established that during the synthesis process, the catalyst is saturated with hydrogen in the reactor, the reduction reaction of the MADE proceeds, and the deactivation by the sulfide ion and the surface of the catalyst undergoes certain changes: the roughness of the surface increases, and the size of the agglomerates and crystallites decreases. The process of controlled partial deactivation of nickel active sites by sulfide ion on the activity of supported catalysts was carried out, the ratios of the surface atoms of nickel, hydrogen and sulfur in catalytic systems with different activities were calculated. It is shown that when the nickel catalyst surface is deactivated by sulfide ions in proportions of 1 sulfur atom per 2 surface nickel atoms, the activity of the catalyst is reduced by $90 \%$ and cannot be subsequently restored.

Keywords: liquid-phase hydrogenation, maleic acid diethyl ether, modifying agents, skeletal and deposited nickel catalyst, active metal, the effect of structural sensitivity of the catalyst. 


\section{1. Введение}

В настоящее время абсолютное большинство многотоннажных производств, включающих стадию гидрирования, протекают в присутствии гетерогенных катализаторов на основе переходных металлов. Основными проблемами использования металлических катализаторов являются: практически полное отсутствие научно-обоснованных подходов к синтезу, низкая селективность, высокая чувствительность к наличию в системе каталитических ядов, незначительные возможности регенерации [1-4]. Известно, что каталитические свойства металлов определяются, в первую очередь, их адсорбционной способностью по отношению к участникам реакции, которая в свою очередь зависит от условий синтеза и выбранных условий протекания процесса. Распределение каталитически активных центров поверхности в зависимости от природы катализатора, в том числе, содержащего промотирующие добавки, достаточно хорошо освещено в литературе $[3,5,6]$, при этом, влияние каталитических ядов на активность катализаторов гидрогенизации значительнее, чем любых промотирующих добавок [7].

Энергетическая неоднородность активной поверхности металла проявляет себя в образовании различных адсорбционных форм реагирующих веществ, для реакций гидрогенизации - главным образом - водорода [8], обладающих различной реакционной способностью. В работе [9] для оценки реакционной способности адсорбированного водорода было предложено использовать метод региональных скоростей, согласно которому общая скорость реакции будет численно равна сумме скоростей на разных типах активных центров поверхности. Метод региональных скоростей, в применении к процессам гидрогенизации должен предполагать процедуру согласования количества адсорбированного водорода и экспериментальных значений скорости реакции. В этом случае экспериментальная задача сводится к получению набора однотипных катализаторов с разными количествами адсорбированного водорода и разными значениями каталитической активности, которая и будет определяться наличием доступных активных центров поверхности. Решение данной задачи позволит прогнозировать активность, селективность и время жизни катализаторов реакций гидрогенизации на основе переходных металлов.

Именно с этой целью, для повышения вариативности системы, с целью увеличить количество однотипных катализаторов с разным содержанием водорода, было решено использовать каталитический яд, который бы блокировал отдель- ные центры поверхности, снижая тем самым общую адсорбционную способность катализатора. Подобные исследования были проведены для скелетного никелевого катализатора $[9,10]$. Тем не менее, данные исследования имели ряд недостатков. Один, из которых заключается в наличии сильного эффекта адсорбционной деформации [11], приводящего, в том числе и к значительному росту активности вследствие уменьшения размера частиц и, следовательно, росту величины удельной поверхности [12]. Такие эффекты затрудняют анализ характера дезактивации, например, использование методики Бартоломью [13] для оценки селективности дезактивации. В результате вышеперечисленных причин было решено использовать нанесённый никелевый катализатор, так как параметры нанесённых частиц лежат в наноразмерной области, а носитель был выбран с максимумом распределения, приходящимся на 5 мкм, таким образом, адсорбционная деформация не должна оказывать значительного эффекта.

Известно, что при синтезе нанесённого катализатора гидрирования (в т.ч. никелевого) восстанавливается не весь металл $[4,7,14]$. При этом, каталитический яд может адсорбироваться, как на восстановленном металле, так и на его соединениях (оксиде), так и на самом носителе. Чтобы учесть влияние адсорбции каталитического яда не активным металлом, а другими компонентами катализатора, было решено использовать в работе катализатор с разным количеством нанесённого и восстановленного никеля.

Целью данной работы было изучение влияния частичной дезактивации сульфид-ионом нанесённого никелевого катализатора на кинетику гидрогенизации двойной связи углерод-углерод на примере диэтилового эфира малеиновой кислоты при избыточном давлении водорода, а также на структурно-механические свойства нанесённого никелевого катализатора на силикагеле.

\section{2. Экспериментальная часть}

\section{1. Синтез никелевых катализаторов на силикагеле}

В работе были использованы катализаторы с разным процентом нанесения никеля на подложку. В качестве подложки был использован «Силикагель Л 5/40м». Средний радиус частиц 5 мкм, удельная поверхность $355 \pm 5 \mathrm{~m}^{2} / \Gamma$.

Нанесённые никелевые катализаторы готовили путём осаждения нитрата никеля на подложке с последующим его разложением и стадией газофазного восстановления по следующей методике. 
Навеску носителя помещали в водный раствор $\mathrm{Ni}\left(\mathrm{NO}_{3}\right)_{2}$ (7,5 г носителя на 100 мл раствора), после чего дожидались адсорбционного равновесия при постоянном перемешивании и температуpe $303 \mathrm{~K}$ в течение 4 часов. Далее подложку с адсорбированным на поверхности $\mathrm{Ni}\left(\mathrm{NO}_{3}\right)_{2}$ отфильтровывали и подвергали прокаливанию при $350{ }^{\circ} \mathrm{C}$ в атмосфере аргона в течение 3 часов до полного разложения нитрата никеля, затем восстанавливали полученный нанесённый оксид никеля молекулярным водородом в газовой фазе при температуре $450{ }^{\circ} \mathrm{C}$. Восстановленный катализатор переносили в жидкую фазу (воду или водные растворы) в атмосфере водорода с последующим насыщением водородом в жидкой фазе при $30{ }^{\circ} \mathrm{C}$. Предложенный способ позволяет получать никелевый катализатор на различных подложках с различным количеством нанесённого катализатора путём варьирования концентрации исходных растворов нитрата никеля [13]. Режим подъёма температуры при восстановлении нанесённого оксида никеля подбирался таким образом, чтобы размер частиц полученного катализатора был минимальным [13].

В работе был синтезирован ряд нанесённых на силикагель никелевых катализаторов, с различным содержанием металла. На рис. 1 представлены зависимости концентраций количеств нанесённого (А) и активного (Б) металла, образовавшегося при восстановлении катализатора в выбранном режиме.

\section{2. Условия проведения жидкофазной реакиий гидрогенизащии}

Процесс гидрогенизации проводили статическим методом, в закрытой системе при интенсивном перемешивании жидкой фазы, исключающем влияние внешнего массопереноса на результаты эксперимента. Конструкция жидкостного реактора позволяла измерять скорость реакции гидрогенизации по объёму водорода, поглощённому в ходе реакции, при интенсивном перемешивании реакционной среды. В условиях эксперимента скорость перемешивания составляла 60 об/с, температура $30^{\circ} \mathrm{C}$. Избыточное давление водорода в системе составляло $0,8 \mathrm{MПа.}$

В качестве гидрируемого соединения выбрали ДЭМК. Использование ДЭМК в качестве модельного соединения объясняется следующим: согласно данным литературы вид кинетических кривых жидкофазного восстановления молекул с двойной связью «углерод-углерод» однотипен [15, 16], при этом реакция идёт одностадийно, без образования побочных соединений.

В качестве растворителя использовали воду, как один из самых хорошо изученных растворителей.

В качестве дезактивирующего агента был выбран сульфид натрия, так как соединения серы, в том числе содержащие сульфид-ион, являются наиболее изученными каталитическими ядами,
A

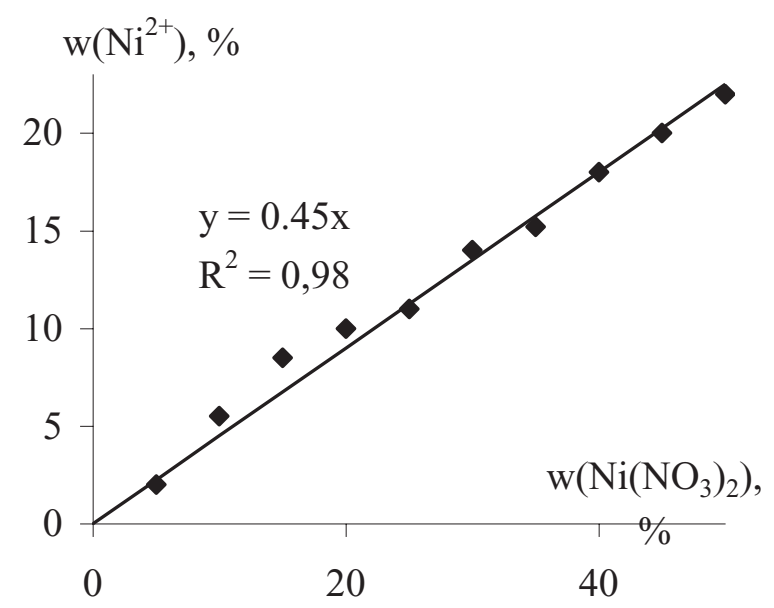

Б

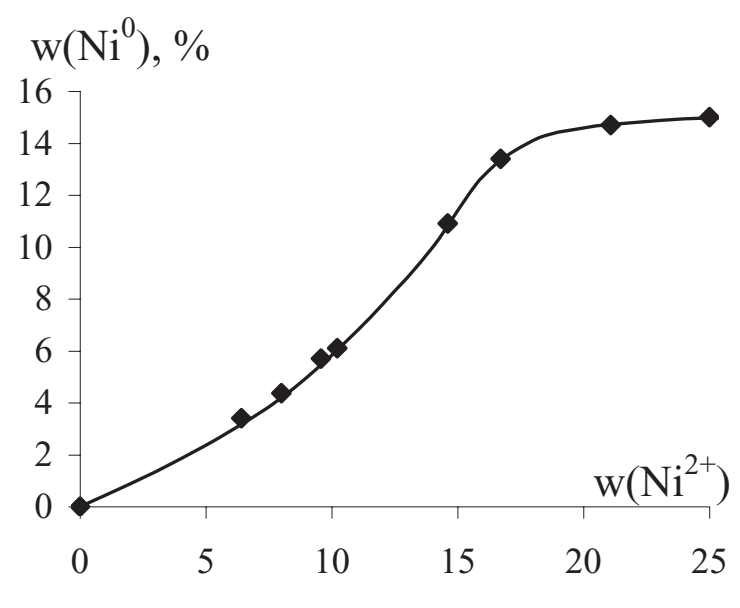

Рис. 1. Нанесение никеля на подложку:

а) зависимость концентрации нанесённого оксида никеля от конџентрации раствора нитрата никеля;

б) зависимость концентрации активного никеля от общего количества нанесённого оксида на силикагеле при восстановлении катализатора в токе водорода. Условия восстановления: $298 \div 723$ К, скорость подъёма mемпературь $4 \mathrm{~K} /$ мин 
значительно понижающими активность катализаторов реакций гидрогенизации [2, 11]. При этом, согласно данным литературы $[2,3,11]$, атомы серы, блокирующие активные центры поверхности катализатора, могут служить инструментом смещения адсорбционного равновесия между индивидуальными формами адсорбированного водорода на поверхности катализатора. Таким образом, сульфид натрия наиболее подходит для решения поставленной задачи и тонкой регулировки каталитической активности скелетного никеля в рамках поставленной задачи.

\section{3. Определение структурно-механических характеристик катализатора}

Гранулометрический анализ полученных образцов катализатора был выполнен с помощью лазерного гранулометра Analysette 22 Compact фирмы Fritsch.

Удельная поверхность определялась с помощью аппаратного комплекса «Sorbi MS», методом низкотемпературной адсорбции азота по методу БЭТ.

Рентгенофазовый анализ (РФА) проводили на дифрактометре Bruker D8 Advance с использованием $\mathrm{Cu}_{\mathrm{K \alpha}}$ - излучения $(\lambda=0,15406$ нм). Для идентификации данных рентгенофазового анализа использовалась база данных PDF-4 и кристаллографическая база данных МИНКРИСТ.

Микрофотографии получены с помощью растрового электронного микроскопа VEGA 3 TESCAN. По микрофотографиям с помощью режима SE определена морфология частиц катализатора, с помощью режима BSE - дисперсия агломератов никеля по размеру. Для определения среднего размера агломерата никеля делалось 200 замеров диаметра частицы.

\section{4. Методика экспериментального измерения количества восстановленного металла}

Определение количества восстановленного металла, нанесённого на подложку, определялось следующим образом. Катализатор восстанавливали согласно пункту 2.1. Далее, сразу после восстановления при температуре $450{ }^{\circ} \mathrm{C}$, не разбирая реактор, вся система насыщалась аргоном. После насыщения системы аргоном скорость потока газа выставлялась $20 \pm 5 \mathrm{~cm}^{3} /$ мин. Далее начинали поднимать температуру с $450{ }^{\circ} \mathrm{C}$ до $600{ }^{\circ} \mathrm{C}$ при постоянной подаче аргона в систему. Вывод газа из системы осуществлялся через гидрозатвор. Скорость подъёма температуры составляла $2^{\circ} \mathrm{C} /$ мин. При достижении $600{ }^{\circ} \mathrm{C}$ реактор охлаждали до $25^{\circ} \mathrm{C}$.
Данное нагревание в токе аргона осуществлялось для десорбции водорода с поверхности катализатора [17].

После охлаждения катализатора до $25{ }^{\circ} \mathrm{C}$, он переносился под слоем воды в герметизируемый стеклянный реактор с двойными стенками для циркулирования теплоносителя (вода, термостатируемая при $\left.25^{\circ} \mathrm{C}\right) . \mathrm{K}$ реактору подключали систему измерительных бюреток для определения объёма газа в системе, а также подачу аргона для вытеснения воздуха из системы. После вытеснения воздуха из системы выключали подачу аргона, герметизировали систему, вводили в систему раствор $\mathrm{HCl}$, не нарушая герметичности, включали перешивание и измеряли количество выделившегося газа.

Масса катализатора в опыте составляла $1 \div 5$ г, масса дистиллированной воды - 50 г, объём раствора $\mathrm{HCl}-20$ мл ( $\rho=1,2$ г/мл).

Известно [18], что при реакции с соляной кислотой, только восстановленный никель будет давать молекулярный водород, в остальных случаях газообразных продуктов образовываться не будет при данных условиях. Таким образом, по количеству выделившегося водорода (данные по объёму приведены к н.у.) можно вычислить количество восстановленного никеля.

\section{3. Обсуждение результатов}

В работе исследованы структурно-механические свойства полученных образцов катализатора в зависимости от количества нанесённого никеля, пример рентгенограмм полупродуктов и катали-

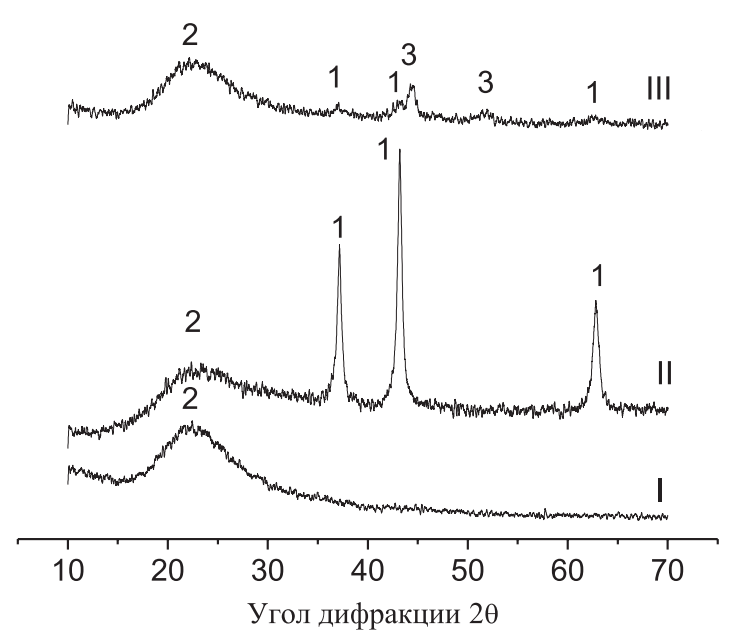

\section{Рис. 2. Рентгенограммы катализатора} и его прекурсоров:

I- чистый силикагель; II - 22 масс.\% нанесённого никеля (Ni общ в форме оксида); III - восстановленный образец II до 14,7 масс.\% $\mathrm{Ni}^{\circ}$ 
заторов представлены на рис. 2. (рефлексы: № $1-$ $\mathrm{NiO}$; № 2 - силикагель; № 3 - Ni).

Анализ данных рентгеновской дифракции показывает, что с ростом концентрации нанесённого оксида никеля от 4,7 до 23,2 масс.\% размер областей когерентного рассеяния (ОКР) увеличивается с 7,0 до 18,0 нм, также растёт степень кристалличности нанесённого оксида. Необходимо учитывать, что обычно размер ОКР меньше размера кристаллита, так как он не включает в себя внешние аморфизированные слои кристаллита [19, 20]. После восстановления катализатора водородом в выбранных условиях характеристические пики, отвечающие за оксид никеля, становятся незначительными, проявляются рефлексы, отвечающие за металлический никель.

В работах $[4,21]$ экспериментально доказано, что активность никелевого катализатора определяется структурой поверхности, на которой присутствуют кристаллиты с межплоскостным расстоянием: 5,6 А, для скелетного никеля подобным кристаллитам соответствуют пики $2 \Theta=54^{\circ}$ и $43^{\circ}$, размер кристаллитов в данном случае составляет 130-160 А. При восстановлении исследованных в работе образцов $\mathrm{NiO} / \mathrm{SiO}_{2}$, согласно результатам обработки рентгенограмм (пример приведён на рис. 2) 70 \% нанесённого оксида переходит в металлический никель с характерными для активной поверхности структурными свойствам. Основные структурно-механические свойства исследованных образцов катализатора и условия их синтеза приведены в табл. 1.

Согласно анализу экспериментальных и литературных данных [4, 7, 13], каталитическая активность нанесённых никелевых катализаторов в несколько раз превышает активность скелетного никелевого катализатора типа Ренея, например, при жидкофазной гидрогенизации ДЭМК в аналогичных условиях на нанесённом никеле (концентрация активного металла $10 \%$ ) активность более чем в 5 раза превышала активность скелетного никеля. Кинетические кривые для реакции восстановления ДЭМК на нанесённом никеле для раз- личного количества активного металла представлены на рис. 3. Количество гидрируемого соединения соответствовало $200 \mathrm{~cm}^{3}$ водорода, что согласно методике измерения активности каталитических систем [22] достаточно для того, чтобы судить о величинах активности катализатора.

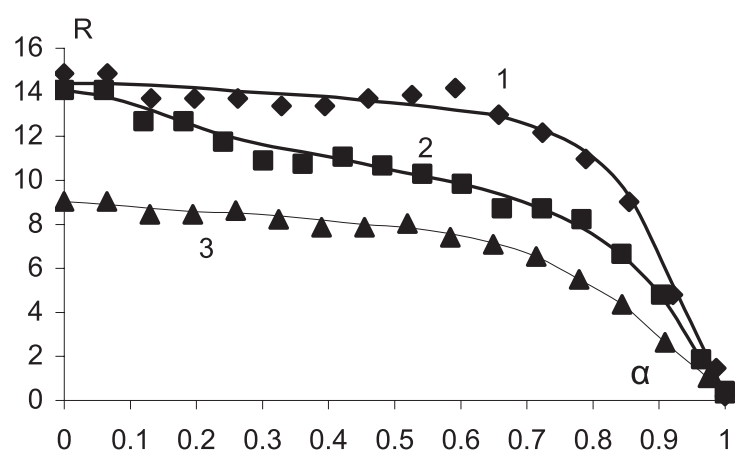

Рис. 3. Скорость поглощения водорода при реакции гидрогенизации ДЭМК в воде на образцах катализатора с различным количеством восстановленного металла,

где $R\left(\mathrm{~cm}^{3}\left(\mathrm{H}_{2}\right) \cdot(c \cdot 2(\mathrm{Ni}))^{-1}\right)$ - скорость реакиии, $\alpha$ - степени превращения степени превращения, количество восстановленного металла: $\checkmark 1-14,7 \% ; \mathbf{\square}-10,9 \% ; \mathbf{\Delta} 3-3,4 \%$.

Условия проведения гидрирования: $T-30{ }^{\circ} \mathrm{C}$; $m_{\text {кат }}-2,177$ г; избыточное давление водорода - 0,8 МПа

Активность исследуемых катализаторов рассчитывали, как наблюдаемые скорости, при степенях превращения 0,2. Зависимости активности от количества нанесённого никеля имеют сложный, не монотонный характер, но всё же активность симбатна количеству нанесения никеля. В свою очередь количество нанесения никеля, размер кристаллитов никеля и агломератов никеля также симбатны между собой. Полученные экспериментальные данные по кинетике можно объяснить изменением доступной поверхности катализатора в результате блокировки пор при больших концентрациях никеля, а также смещением равно-

Таблица 1

Условия синтеза и структурно-механические свойства катализаторов

\begin{tabular}{|c|c|c|c|c|c|c|c|}
\hline № & $\begin{array}{c}\text { Macca } \\
\mathrm{Ni}\left(\mathrm{NO}_{3}\right)_{2} \\
\text { на } 1 \text { г } \mathrm{SiO}_{2} \\
\text { в pactворе }\end{array}$ & $\begin{array}{l}S_{y,}, \\
M^{2} / \Gamma\end{array}$ & $\begin{array}{c}\text { Количество } \\
\text { активного } \\
\text { металла, } \\
\text { \% }\end{array}$ & $\begin{array}{c}\text { Радиус частиц } \\
\text { катализатора, } \\
\text { мкм }\end{array}$ & $\begin{array}{c}\text { Размер } \\
\text { кристалл., } \\
\text { нм }\end{array}$ & $\begin{array}{c}\text { Межатомные } \\
\text { расстояния, } \\
\AA\end{array}$ & $\begin{array}{c}\text { Средние } \\
\text { размеры } \\
\text { агломератов } \\
\text { никеля, нм }\end{array}$ \\
\hline 1 & 6,7 & 264 & 14,7 & 5 & 17,7 & 7,4 & 146 \\
\hline 2 & 4,3 & 317 & 10,9 & 5 & 15,5 & 6,8 & 127 \\
\hline 3 & 2,2 & 362 & 3,4 & 5 & 10,0 & 5,5 & 116 \\
\hline
\end{tabular}


весия индивидуальных адсорбционных форм реагирующих веществ, главным образом водорода. Кроме того, увеличение кристалличности частиц и общий рост объёма никеля в частице должны приводить к увеличению лабильности водорода адсорбированного и абсорбированного поверхностью металла [23]. Такое увеличение лабильности, очевидно $[8,9]$, должно приводить так же к росту активности катализатора.

Анализ кинетических данных показал, что каталитические системы с различными количествами активного металла не имеют строгой симбатной зависимости наблюдаемых параметров активности от количества введённого дезактивирующего агента на 1 г никеля. Кроме того, согласно данным [11], при дезактивации серой активность скелетного никелевого катализатора полностью исчезает при введении 1 атома серы на 8 поверхностных атомов никеля, а в случае исследованных образцов для дезактивации катализатора требовалось увеличить соотношения $\mathrm{Ni}: \mathrm{S}$ на поверхности катализатора в 3-5 раза, при этом в обоих случаях адсорбция серы носила необратимый характер. Данный факт может отчасти быть объяснён адсорбци- ей серы на свободной от никеля поверхности силикагеля и на оставшемся невосстановленном оксиде никеля, что подтверждается отдельными экспериментами, однако, несмотря на это, устойчивость нанесённого никеля значительно превосходит массивные катализаторы. Параметры активности частично дезактивированного $\mathrm{Ni} / \mathrm{SiO}_{2}$ и соотношения атомов в каталитической системе приведены в табл. 2 .

В табл. 2 приведены соотношения атомов металлического никеля и серы к максимальной величине адсорбции водорода. Согласно различным источникам $[24,25]$, в зависимости от типа граней монокристалла на поверхности никеля может содержаться от $1,14 \cdot 10^{19}$ до $1,86 \cdot 10^{19} \mathrm{aT} / \mathrm{M}^{2}$, для расчёта брали среднюю величину. Максимальное количество реакционноспособного водорода определяли с помощью комплекса термического анализа и масс-спектрометрии, а также методом адсорбционной калориметрии, подробно методика описана в работе [26]. Сравнение активности катализатора с долей не занятой сульфидом активной поверхности металла показывает, что дезактивация катализатора протекает значительно легче при уменьше-

Таблица 2

Активность катализаторов в реакции восстановления двойной связи «углерод-углерод» при степенях превращения 0,2 в воде при температуре 303 К и избыточном давлении водорода 0,8 МПа

\begin{tabular}{|c|c|c|c|c|c|}
\hline $\begin{array}{c}\text { Количество } \\
\text { введённого } \\
\mathrm{Na}_{2} \mathrm{~S}, \\
\text { ммоль/ г Ni }\end{array}$ & $\frac{\mathbf{R}_{\mathrm{h}},}{\mathrm{cm}^{3}\left(\mathrm{H}_{2}\right) / \mathbf{M и H ~ \Gamma ~ N i}}$ & $\begin{array}{c}\mathbf{k}_{\mathrm{H}} \\
\text { по ДЭМК, } \\
\mathbf{c}^{-1}\end{array}$ & $H_{a d s}^{\max }: \mathbf{S}$ & $\mathrm{Ni}^{\circ}: \mathrm{S}$ & $\begin{array}{c}\text { Доля активной } \\
\text { поверхности, } \\
\text { не занятой } \\
\text { сульфид-ионом, \% }\end{array}$ \\
\hline \multicolumn{6}{|c|}{$\mathrm{Ni}^{\circ} 14,7 \% / \mathrm{SiO}_{2}$} \\
\hline 0 & 15,31 & 590 & $1: 0$ & $1: 0$ & 100 \\
\hline 0,21 & 14,24 & 449 & $1: 0,6$ & $1: 0,11$ & 89 \\
\hline 0,42 & 8,01 & 252 & $1: 1,2$ & $1: 0,22$ & 78 \\
\hline 0,63 & 4,93 & 155 & $1: 1,8$ & $1: 0,33$ & 67 \\
\hline 0,84 & 2,61 & 82 & $1: 2,4$ & $1: 0,44$ & 56 \\
\hline \multicolumn{6}{|c|}{$\mathrm{Ni}^{\circ} 10,9 \% / \mathrm{SiO}_{2}$} \\
\hline 0 & 14,52 & 458 & 1:0 & $1: 0$ & 100 \\
\hline 0,1 & 6,14 & 193 & $1: 0,28$ & $1: 0,058$ & 94,2 \\
\hline 0,2 & 3,07 & 96 & $1: 0,57$ & $1: 0,11$ & 89 \\
\hline 0,3 & 1,61 & 50 & $1: 0,86$ & $1: 0,17$ & 83 \\
\hline 0,4 & 0,87 & 27 & $1: 1,15$ & $1: 0,23$ & 77 \\
\hline \multicolumn{6}{|c|}{$\mathrm{Ni}^{\circ} 3,4 \% / \mathrm{SiO}_{2}$} \\
\hline 0 & 6,2 & 346 & $1: 0$ & $1: 0$ & 100 \\
\hline 0,5 & 5,29 & 167 & $1: 1,43$ & $1: 0,73$ & 27 \\
\hline 1,0 & 3,33 & 105 & $1: 2,87$ & $1: 1,46$ & 0 \\
\hline 1,5 & 1,58 & 49 & $1: 4,31$ & $1: 2,2$ & 0 \\
\hline
\end{tabular}


нии концентрации металлического никеля на поверхности катализатора. Приведённые соотношения атомов $\mathrm{Ni}^{\circ}: \mathrm{S}$ почти во всех исследуемых системах имеют значения меньше единицы, это косвенно подтверждает факт протекания процесса адсорбции серы на металлическом никеле в мономолекулярном слое. При дезактивации поверхности катализатора сульфид-ионами в пропорциях 1 атом серы на 2 атома никеля активность катализатора снижается на 90 \% и впоследствии не восстанавливается.

На рис. 7 представлены SE изображения поверхности нанесённого никеля на $\mathrm{SiO}_{2}$ до восстановления (а), после восстановления (б) и после процесса дезактивации (г). Основная часть исследуемых катализаторов - частицы диаметром 5 мкм с достаточно гладкой поверхностью, форма частиц - неправильные многогранники.

Полученные в работе данные позволяют утверждать, что в ходе процесса синтеза, предварительного насыщения катализатора водородом в реакторе, протекании реакции восстановления ДЭМК, процесса дезактивации сульфид-ионом, поверхность катализатора претерпевает определенные изменения - увеличивается шероховатость поверхности, уменьшается размер агломератов и кристаллитов. Однако, в отличие от массивных никелевых катализаторов функции распределения частиц которых заметно изменяются (максимум распределения смещается к частицам с меньшим радиусом [13]), функция распределения частиц по радиусу у исследуемых образцов катализатора практически не изменялась на каждом этапе синтеза катализатора и в процессе гидрогенизации
ДЭМК, средний размер частиц катализатора оставался равным 5 мкм. Полученные данные объясняются эффектом адсорбционных деформаций массивных металлических катализаторов и практически полной инертностью частиц носителя к процессам, протекающим при синтезе и в ходе проведения реакции гидрогенизации. При этом, хотя линейные размеры частиц носителя практически не изменяются, поверхность частиц всё же претерпевает значительные изменения. Важно отметить, что адсорбционная деформация оказывает эффект именно на агломераты никеля, т.е. деформация идёт именно там, где идёт реакция гидрогенизации. Эффект изменения структуры поверхности катализатора под влиянием различного гидродинамического режима, повышенного давления, природы растворителя, адсорбции реагирующих веществ, протекания реакций гидрогенизации, процесса дезактивации можно назвать относительной структурной чувствительностью катализатора, которая численно может быть выражена как фрактальная размерность поверхности исследуемых образцов $\mathrm{Ni}^{\circ} / \mathrm{SiO}_{2}$ после протекания одного из технологических процессов, отнесённая к фрактальной размерности свежеприготовленного катализатора. На практике такой эффект изменения структурно-механических свойств поверхности катализаторов на основе переходных металлов под действием условий проведения процесса хорошо объясняет многие кинетические закономерности жидкофазных реакций гидрогенизации, а корреляции численных значений относительной структурной чувствительности катализатора с условиями протекания реакций даёт возможность

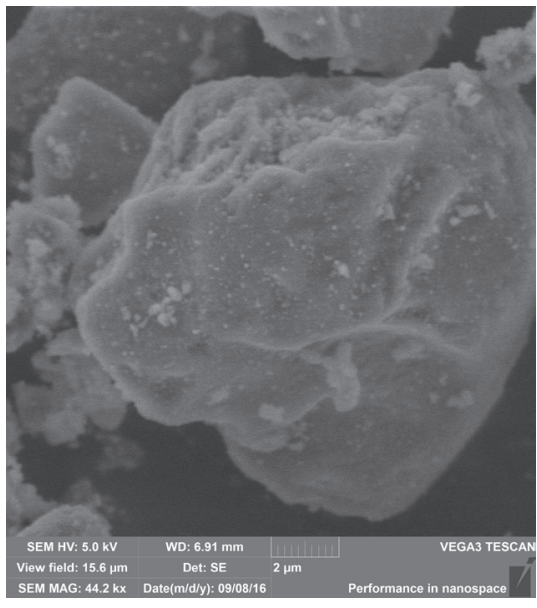

$a$

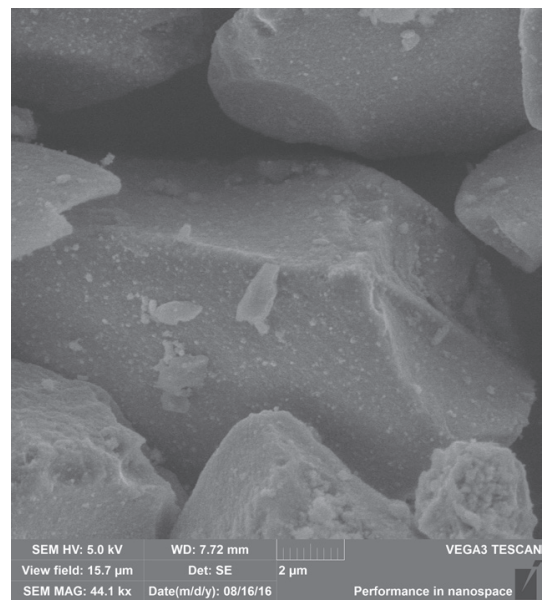

$\sigma$

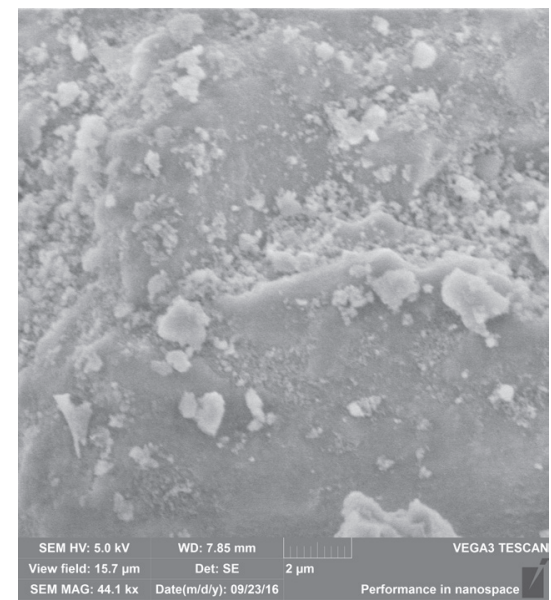

B

Рис. 4. Микрофотографии образцов катализатора (РЭМ):

$a-\mathrm{NiO} / \mathrm{SiO}_{2} ; \sigma-\mathrm{Ni} / \mathrm{SiO}_{2} ;$ в - $\mathrm{Ni} / \mathrm{SiO}_{2}$ при введении 0,63 ммоль $\left(\mathrm{S}^{2-}\right) / 2 \mathrm{Ni}{ }^{\circ}$

(во всех образцах $\omega\left(N i_{\text {оби }}\right)=22$ масс.\%, в образие (б) $\omega\left(N i^{\circ}\right)=14,7 \%$, поле обзора 15,7 мкм) 
прогнозировать скорость реакции и характер кинетических кривых.

Слабо выраженное изменение эффекта относительной структурной чувствительности позволяет по методике, предложенной в работах [3, 10, 11] использовать нанесённые никелевые катализаторы для экспериментального определения реакционной способности индивидуальных активных центров поверхности и связанных такими центрами реагирующих веществ, что в свою очередь позволит прогнозировать селективность никелевых катализаторов в реакциях жидкофазной гидрогенизации.

Работа выполнена в рамках Государственного задания. План работы согласован с НИР Научного совета РАН по физической химии на 2019 (№ 19-03460-07). Исследование проведено с использованием ресурсов Центра коллективного пользования научным оборудованием ФГБОУ ВО «ИГХТУ».

\section{Лumepamypa}

1. Крылов О.В. Гетерогенный катализ. М.: ИКЦ «Академкнига», 2004. 679 с.

2. Хьюз $P$. Дезактивация катализаторов. М.: Химия, 1989. $280 \mathrm{c}$.

3. Островский Н.М. Кинетика дезактивации катализаторов: математические модели и их применение. М.: Наука, 2001. 335 с.

4. Anderson J. R. Структура металлических катализаторов. М.: Мир, 1978. 485 с.

5. Клячко А.Л. Кинетика и катализ. 1978. Т. 19. №5. C. 1218-1223.

6. Navalikhina M.D., Krylov O.V. Russian chemical reviews. 1998. T. 67. № 7. C. 587-616.

7. Afineevskii A.V., Osadchaia T.Yu., Prozorov D.A. Trends in Green Chem. 2016, 2:1. DOI: 0.21767/24719889.100012.

8. Койфман О.И., Улитин М.В. Проблемы термодинамики поверхностных явлений и адсорбции. Иваново: ГОУ ВПО Иван. гос. хим.-технол. ун-т., 2009. $256 \mathrm{c}$.
9. Прозоров Д.А., Лукин М.В. Вестник Тверского государственного университета. Серия: Химия. 2013. № 15. C. 168-174.

10. Lukin M.V., Prozorov D.A., Ulitin M.V. Kinetics and Catalysis. 2013. T. 54. №4. C. 412-419. DOI: 10.1134/ S0023158413040101.

11. Заливин С.Н. Журнал физической химии. 2008. T. 82. № 2. С. 398-400.

12. Афинеевский А.В., Прозоров Д.А., Осадчая Т.Ю., Лукин М.В. Известия ВУЗов. Химия и химическая технология. 2015. Т. 58. № 11. С. 40-44.

13. Bartholomew C.H. Applied Catalysis A: General. 2001. T. 212. № 1. C. 17-60. DOI: 10.1016/S0926860X(00)00843-7.

14. Zhao A. Catalysis Communications. 2012. T. 17. C. 3438. DOI: 10.1016/j.catcom.2011.10.010.

15. Lukin M.V., Afineevskii A.V. Protection of Metals and Physical Chemistry of Surfaces. 2013. T. 49. №4. C. 451-454. DOI: $10.1134 / \mathrm{S} 2070205113040102$.

16. Мохов В.М., Попов Ю.В., Небыков Д.Н. Известия ВолгГТУ. 2012. Т. 5. №9. С. 38-43.

17. Boudjahem A.G. Catalysis letters. 2002. T. 84. № 1-2. C. 115-122. DOI: 10.1023/A:1021093005287

18. Пешкова В.М., Савостина В.М. Аналитическая химия никеля. М.: Наука, 1966. 205 с.

19. Гордина Н.Е., Прокофьев В.Ю., Кочетков С.П. Рос. хим. ж. (Ж. Рос. хим. об-ва. Им. Менделеева). 2016. T. LX. № 2. C. 39-47.

20. Il'in A.A., Rumyantsev R.N., Veisgaim V.V. Russian Journal of Physical Chemistry A. 2016. T. 90. №4. C. 764-770. DOI: 10.1134/S0036024416040105.

21. Сатыбалдиева Н.К., Омирбай Р.С., Батесова Ф.К. Вестник КазНТУ. 2015. №4. С. 517-520.

22. Прозоров Д.А., Лукин М.В., Улитин М.В. Известия ВУЗов. Химия и химическая технология. 2010. Т. 53. № 2. С. 125-128.

23. Черданиев Ю.П., Чернов И.П., Тюрин Ю.И. Томск: ТПУ. 2008. Т. 286.

24. Закумбаева Г.Д. Взаимодействие органических соединений с поверхностью металлов VIII группы. Алма-Ата: Наука, 1978. 303 с.

25. Сокольский Д.В. Гидрирование в растворах. АлмаАта: Наука, 1979. 436 с.

26. Прозоров Д.А., Смирнов Н.Н., Афинеевский А.В. Известия ВУЗов. Химия и химическая технология. 2015. T. 58. № 2. С. 83-84. 